\title{
INVESTIGATING AND ANALYZING THE AMBIGUITY IN THE CONCEPT OF INFIDELITY IN THE “TAMHIDAT" OF EIN AL QOZZAT HAMEDANI
}

\author{
Shokrallah PouralKhas ${ }^{1}$ \\ Ahmad Jabari ${ }^{2}$ \\ Farshid Bagheri ${ }^{3}$
}

\begin{abstract}
Ambiguity is one literary technique that speaks to beauty and influence. But in prose texts and especially mystical texts it adds complexity and misunderstanding. The concept of infidelity has some ambiguities in the Qur'anic context in the "Tamhidat" that we refer to as contradictions. Contrary to the seven divisions cited by linguists for ambiguity, the major ambiguity in the measures of disbelief is the contradiction and contradiction. This is due to the type of experience on the one hand, and the chosen language (Farsi) on the other. In addition to the cultural and political causes of the type of government, mystical texts have also been implicated in misunderstandings.
\end{abstract}

Keywords: Ambiguity, Disbelief, Tamhidat, Contradiction

\section{Introduction}

One of the problems with mystical texts is to understand its exact and explicit meanings. The issue of ambiguity, not only in the field of language and philosophy, but also in the field of literature and mysticism, leads to a multiplicity of semantics and sometimes misperceptions. The historical view of Sufism and Sufism is fraught with misunderstandings, polysemy and a combination of concepts that have led to the trial and even rejection and murder of some.

Although ambiguity and consequently ambiguity is one of the literary and linguistic issues, the

\footnotetext{
${ }^{1}$ Associate Professor, Department of Persian Language and Literature, University of Mohaghegh Ardabili. Ardabil, Iran. Corresponding Author Email: pouralkhas@uma.ac.ir ${ }^{2} \mathrm{PhD}$, Department of Persian Language and Literature, Urmia University, Urmia, Iran.

${ }^{3}$ Ph.D student, Department of Persian Language and Literature, Shiraz University, Shiraz, Iran.
} 
complexity and linguistic complexity of the language and the type of language used in mystical texts has always been a challenge between Sophia and the audience. Is. He has written numerous commentaries and interpretations of the sentences of elders, treatises, and books. In reading mystical texts, we often encounter literary text. At times beyond this literary context, we also see a particular language that causes ambiguity in understanding and understanding.

\section{A brief look at Hamadani's Life and}

\section{Works}

Abu al-Ma'ali ibn Abdullah bin Abi Bakr Muhammad ibn Ali ibn alHassan ibn Ali al-Mijani was born in the city of Hamadan in the year 1974. His grandfather is an intermediary. (Hamadani, 2010: 45) Although the judge is originally from Azerbaijan, he mentions his birth in Hamadan: the stem of [Ahmad al-Ghazali] al-Hamdani and Muscat Rasi (Hamadani, 2000: 7). Father Ein al-Qadzat's sources have also been martyred in the Middle City (Rak, Hamedani, 2010: 45).

His life and education in Hamadan past, and in particular the influence of Ahmad al-Ghazali on him, is undeniable. However, Afif Asiran: As of childhood, Abu al-Maali and his education in the works of note-takers and historians have not been mentioned. There is also no mention of his intellectual and spiritual state until his twenties, but one can find interesting information in his two books, Zubdat alHaqqiq and Shekvat al-Gharib (Hamedani, 2010: 46). There is an escape from his view of the world and his perception of religion and his way of thinking.

\section{Research Background}

Davari Ardakani, Negar, (1996) In his Master's thesis entitled "Investigating Ambiguity, Ambiguity and Uncertainty in Farsi Language", has thoroughly and extensively examined the causes and types of ambiguity in linguistics. This work contains readings about ambiguity. Safavi, korosh (2003), in the second volume of the book "From Linguistics to Literature" has investigated the ambiguity of automatic language. Modaresi, Fateme (2011) in the Descriptive Culture of Criticism and Literary Theories, under the ambiguity of linguistic theories, in particular William Thompson's views. Alston, William (2001), in his book Philosophy 
of Language, analyzes the subject of ambiguity. From the point of view of logic, it has examined Williamson's views. Shiri, Ghahreman (2011), in an article entitled "The Importance and Types of Research Ambiguity," explores research in this area.

\section{Define Ambiguity and its Types}

The ambiguity of the root of 'Baham', the ambiguity of Al-Baba: Ahqa'ah / and Al-Ameri: Lem Jal'al, or Jafar (Maloof, 2007), has the literal meaning of ambiguity, namely, the obscurity of the matter and the ambiguity of the word in its literal sense. Linguistic ambiguity is a phrase that lacks a clear and decisive answer to its various practical uses (Alston, 2001: 135). This definition does not, however, make the nature of "ambiguity" very clear. What factors contribute to the ambiguity of words and sentences? Although ambiguity and consequently considered ambiguity as one of the artistic aspects of poetry, in prose texts and especially mystical texts in terms of both the artistic view of theology and the type of experience at stake, the subject of ambiguity is also the subject of ambiguity. The author and the reader can be reviewed.
The definition of ambiguity, despite the complexity of the word "ambiguity," contains clear sentences. The following is the ambiguity of Martin Gray: ambiguity: bringing a word or sentence that has two meanings, multiple meanings, or uncertain meanings (Gary, 2003: 14 onwards). He has taken into account several signs »1. (Abrams, 2006: 11) Williamson points to two main features of ambiguity, namely three main features of ambiguity: (a) marginal case b) tolerance C. The Confused Boundary (Moradi, 2014: 6-5) Leach considers two main characteristics of "similarity" and "difference": Since "meaning" is an effective factor in understanding the concept of ambiguity, the study Some dimensions of meaning help to better understand the cause of ambiguity. Two important types of semantic communication are: "similarity" and "difference".(Davari Ardakani,1995 :74)

Empson has examined the ambiguity of the seven floors:

When a component of a sentence gives multiple meanings simultaneously.

2. When two or more substitutable meanings are merged together, they create a meaning. 
3. When two completely unrelated meanings are presented simultaneously.

When two substitutionary meanings come together to reveal the complexity of the author's mental state.

5. Some kind of confusion that the author has come up with something new in the process of creating the work. In other words

No longer has he been familiar with that subject or theory in the process of creating the work.

6. Something that is seemingly contradictory and that the reader must interpret.

7. A clear and complete contradiction which shows that the author does not have a clear view of what he has said (Yousefi and Rasoolian, 2013: 170).

We must consider the issue of ambiguity by considering that environmental, political, cultural factors, on the one hand, and agents of the speaker, writer, listener, and reader, on the other hand, contribute to ambiguity and misunderstanding. The examination of the preparations reveals that, in the linguistic sense, there have been two conceptions of the meaning of some sentences and phrases in the minds of scholars and scholars; While we are confronted with a fully experienced mystical text.

\section{Ambiguity in Reading Mystical Texts}

The linguistic features and semantic structure of mystical texts have caused difficulties in reading mystical texts throughout history. Given the ambiguity discussed above, most of the mystical complexities arise from the standpoint of contradiction. In addition to what is left out from the linguist's perspective, the type of personal experience and inexpressibility of language are involved in creating ambiguity. There is a change in attitude towards the meaning or meaning of poetry or mystical text in Persian literature. While exploring the deconstruction of Rumi's poetry, Dr. Purnamdarian points out: If we look at language from the doorway to the door, there are new ways of reading and writing that differ from our languagebased linguistic habits. Due to linguistic habit, we search for the unique meaning that the author has in every text, and the author seeks a meaning that all readers of the text must understand equally. This linguistic habit is the result of a dominant cultural, political, and social system in 
which the relation of the author and the reader is also such as that of the king and the slave, the teacher and the disciple, and the commander and the agent (Purnamdarian, 2013: 20).

We must also pay attention to the differences between Arabic and Persian. The Arabic language was carefully scrutinized by scholars and scholars for its religious structure and support. But for the sake of political and social reasons, Persian was considered the language of poetry and literature rather than the language of politics and religion. Therefore, in the works of Einqat al-Qadzat Hamadani, we come to the profound and obvious difference between the two languages. An examination of the Tamhidat, regardless of the mystical and ideological concepts, reveals that the language of the Tamhidat is poetic and comes from the personal experience of Judge Hamadani. But in his two works, written to defend and complain about the time, we face clear, acceptable and formal language, or in other words, criteria.

Therefore, not only the reading of mystical texts, the meanings of vocabulary, idiomatic problems, and mystical concepts must be taken into account, but also the subject of language and the inexpressibility of mystical experiences in order to avoid mindboggling interpretations. We can in no way depict the author's sense of place in writing a mystical experience. In other words, from the point of view of the author's death, we impose on the text and impose our intended meaning on the text. This is quite evident in the three charges that were set for the trial. It is also possible to come up with new attitudes and interpretations of mystical texts that may have been in the author's mind and language by accepting linguistic deficiencies on the one hand and understanding personal mystical experiences on the other.

\section{Exploring Infidelity from a Vague Perspective}

Sentences and expressions containing the concept of infidelity can be examined on the basis of seven ambiguities. Unbelief is not very ambiguous in expressing Islamic concepts, but along with presenting some Zoroastrian concepts to some readers. Opposition to such statements has often been voiced by the government and its publishers, indicating their intolerance and lack of effort. For example, in this sentence we read: It is unfortunate for the 
poor to say these words. Have you ever seen an infidel Muslim? Hassan and Jamal Muhammad the Prophet (peace be upon him) have disbelieved among the believers, and no one knows! Until these disbeliefs reach the idolatrous faith, and when you see the extent of religious belief and idolatry, the door of "La Elaha ella Allah Mohammad Rasul Allah" will be played and full faith will be at this time; and the perfection of religion and nation. In the meantime. (Hamedani, 2010: 118)

In the Islamic community of that time, the emphasis has been on avoiding disbelief and turning to faith. In other words, disbelief and faith define each other in terms of opposition and opposition. Accuracy shows that we are not faced with lexical ambiguity. What is ambiguous is that the existence of such combinations as infidel Muslim, infidel believers, and the link between infidelity and paganism makes it difficult to understand the text. This kind of ambiguity is expressed by William Empson in No. 6. (Yousefi \& Rasoolian, 2013: 170) The apparent contradiction that Empson mentions and leaves it to the reader in mystical texts and in Especially in the preparations, there are certain consequences; trial and ultimately murder. It seems to us that the root of this must be traced back to the linguistic difference between Arabic and Persian. The Arabic language had a specific framework in terms of its religious background and its relevance to the scholars in the description and description of the Quranic words to give explicit and comprehensive meanings. Especially when we read Judge Hamadani's statement in our defense in Arabic, we no longer face such contradictions. In fact, the language used in personal preparations is of a poetic type rather than a spoken language. mined not from the perspective of contradiction but from the angle of contradiction. The word disbelief, in contrast to the word faith, is not ambiguous in Islamic thought, but in the Tamhidat and wording of the verses that lead to misunderstanding: disbelief and faith above the throne are two veils between God and the servant. For a man must be neither a disbeliever nor a Muslim. Being still in disbelief and in faith still in the two hijabs; and the seeker not ending except in the veil of 'Kabriyyah Allah and Atheat', have you heard what Mustafa says. "For me is with God when there is no angel or prophet" testifies to the secrets of these officials to 
Abdul-Abaddin and Deer al-Dahrain (Hamadani, 2010: 123). Neither does the Muslim not only present the reader with a specific framework of faith and disbelief, but it also makes it difficult to understand the sentence. In other words, does the reader not know what is the limit of non-infidels and Muslims? Judge Hamadani explicitly states the limitations of faith and infidelity in the Treatise of the Truth of Religion. He writes in the first chapter in faith in God and his attributes: To know that the Almighty God is an existence that conceives of no way in him. is not. He is unique and indivisible, a noble and generous, kind and gracious person who has great names and prestige. The hearts of the people at his hands and in the foreheads of the world are Astan Sayyid, and he does not do anything else (Hamadani, 2010: 143).

In fact, such a statement, in opposition to the text of the Tamhidat, implies that he is fully convinced. In the face of personal experiences and the expression of his language, the reader becomes ambiguous. From the standpoint of symbolism, Dr. Musharraf looks at the subject: Sufi must deal with the linguistic problem that results from a serious gap between what he wants to express in words or to describe his personal intuitions. She knows, and what she can really say, what to do to fill this gap. Is there a way? Symbolism may be the first thing that seems (Musharraf, 2004: 6-115) Regardless of the symbolism, the mystical texts, and especially the Tamhidat, are caught up in a sense of semantic contradiction.

What Leach refers to as "similarity" and "difference" (Davari Ardakani, 1996: 74) is not in the literal similarity and difference Tamhidat, but in the specific readings he has experienced in his own world. Therefore, in his mind and language, Islamic concepts and ideas change, a change that the community and religious scholars disagree with. Of course, the history of the semantic transformation of the vocabulary we see in the works of some of the elders, but the literary tradition was that the text had to have a definite meaning; This also led to ambiguity in understanding the meaning.

Ein AL qozzat takes note of the similarities as well and invites readers to understand them carefully: perhaps the things mentioned above are more likely to be useful for retaining the words quoted in the books. Don't pay attention, because often, that exaggeration adds to 
his astonishment and demands the truth of the words quoted and the metaphor and simile make it difficult to question. It deserves to be, to a small degree, content with the rhetoric that comes from the scholars' mouths and from the books of the late scholar, not our critics. When he preserved them, he would hesitate to look at them and take care of them. Do not arbitrarily refer to old books unless the teacher refers to them (Hamadani, 2006: 134). Pornographers point to the point that points to the ambiguity of the poem, and we can generalize this argument as well: There is no doubt that the search for the intention of the author if assumed to be possible is a search that matters And its validity through the adaptation of the interpretation to the structural and meaningful requirements of the text is just as important as the interpretation that is supposed to have revealed and revealed the poet's purposive intent (Purnamdarian, 2002: 213). And the interpretation of the structural requirements in some of the provisions of the provision was not very much in line with the Muslim mind. Judge Hamadani occasionally interprets the concept of disbelief, but the same interpretation did not convince the audience of that day: (67) 'Some of them are just' calls the unbelievers just. What a gonna understand! Medium unbelief is the order of worship, and the middle is through the state, and the end of guidance is no less than half as much as it is due to the transgressors, and the transgressions are also attributed to the guidance "who guides whomever $\mathrm{He}$ wills and misleads whomever He wills". (Hamedani, 2010: 48)

$$
\text { Judge Hamadani uses }
$$

Muhammad and Iblis in the expression and analysis of infidelity. He examines Iblis not in the sense of infidelity, but in terms of one of the divine attributes: Have you ever known that God has two names: one "al-Rahmani al-Rahimi" and the other "al-Jubar al-Mutkebar"? From the trait of dogmatism, Iblis created; and from the trait of mercy, Muhammad. So the attribute of mercy came from Ahmad's food, and the attribute of anger, the food of Iblis. (Hamadani, 2010: 277) Such an impression does not fit in with the Empson weekly classification. Rather, it is an ambiguity in perception that is not preceded by Islamic thought. The world of Islam and its audiences did not tolerate such contradiction at that time.

Ein AL qozzat even uses the category of "love" to explain such a 
concept. This adds to the ambiguity of the concept of infidelity: O Satan the liar of his love came with God! And what happened to Mustafa Danni's guilt? The love of God came with him: to fall in love with the devil of God, his sin came; and to fall in love with the prophet, his sin came, "this is revealed until God has forgiven your past and future." The world must give him a piece of this zen and sin, which he borrowed, and they rendered favor to man and to man; and yet what they said was "ruthless and ignorant." A little bit of this universal sin has been disbelieved, but all of it has fallen on Mustafa (229). In the above words the words are not ambiguous in themselves but in the context of the text the departure from the norm and custom of the time. An examination of such sentences from a historical point of view may well illustrate the evolution of Islamic thought in the geographical domain of Iran.

Judge Hamadani, in discussing infidelity, describes it as a secret. The headline for disbelief is ambiguous. He does not speak this secret correctly and leaves it to the audience to receive. His expression is in the poem's presentation: Look, I did some spying and spying, and I laid some divine secrets in the desert!
However, the unbelievers were told that "the divine secret of unbelief is revealed", though his zeal is mandatory to remove the creatures! But let me be ugly, and the few verses that were issued through rhetoric, though very illadvised, write to us that no one else but the soul of Mustafa-Salam and the beloved of God be aware of the meaning of these bits, but others Not to be heard. There is another knowing and seeing (Hamadani, 2010: 269) He distinguishes between knowing and seeing with seeing and seeing. We do not observe ambiguity in both the lexical and the wording of the text, but the difference in beliefs and language makes the audience unable to understand the text directly.

In spite of its precise appearance, the division of my shelf faces some ambiguities; it is a contradiction and even a contradiction. In one of his divisions, he speaks of true disbelief: I said that disbelief is in all kinds of ears. The disbelief of the soul is in relation to Iblis; and the disbelief of the heart is in relation to Muhammad; and the disbelief of the truth is in relation to God; after that sentence be faith itself. I am so foolish to say these words that do not fit into this world or into that world! But I say, Whatever the wind! (Ibid: 209) 
Judge Hamadani does not speak clearly of what does not fit into this world and that world. The reason for this is in the kind of inexpressible mystical experience and language that flows through the text.

\section{Conclusion}

The concept of infidelity, despite its features in Islamic religion, has been expressed in a different way. The language of preparation has both a literary and an expressive character. Judge Hamadani's language is in the preparation of a poet and, of course, due to his specific experiences, Persian language could literally tell his story from a literary and structural point of view. But in the face of such circumstances, the audience of jurists and scholars sought straightforward and direct access to the text.

The texts of the Tamhidat, and especially the concept of infidelity, are so ambiguous that the audience is perplexed at the meaning of the study. Although ambiguity is a literary subject and adds to the aesthetic of poetry, but in mystical texts, and especially in trial and error, it is not only aesthetic but also profound and profound. Most of the ambiguities have come from the perspective of inconsistency and divergence, based on the definitions and divisions they have made on ambiguity, and according to our review of the measures of disbelief. The reason for this is due to the type of Islamic society's view of infidelity. The view of the Islamic community at that time had a definite framework that was also distinct from the category of faith.

Judge Hamadani in expressing disbelief has introduced new, yet unacceptable, horizontal beliefs by bringing concepts such as true disbelief, light Iblis, Iblis from the attribute of God, virtual faith, and true horizontal disbelief. The cause of this can be examined from a linguistic perspective. The Persian language has some inconsistencies in the expression of some pure mystical experiences. Whereas Arabic, which was a political and cultural language, followed a precise framework. This kind of difference is not in any way the weakness of one language or the strengths of another language, but it does bring to mind that particular experiences of expression become inconsistent and ambiguous.

And the last point is that ambiguity in disbelief is not conceived in terms of words, nor in terms of syntax 
and wording. Therefore, it can be argued that the major ambiguity in mystical texts is the contradiction and contradiction of concepts. A topic to consider in other texts.

\section{References}

Alston, William, (2001), Language Philosophy, Nader Jahangiri Translation, Mashhad, Ferdowsi University of Mashhad

Pournamdarian, Taghi, (2013), Aftab Daraye, Tehran, Sokhan, Fourth Edition

Purnamdariyan, Taghi, (2002), Cloudy House, Tehran, Soroush, Second Edition

Davari Ardekani, Negar, (1996), Investigation of ambiguity, ambiguity and ambiguity in Persian language, Tarbiat Modarres University, M.Sc.

Safavi, Korosh, (2003), From Linguistics to Literature Volume II, Tehran, Surah Mehr, First Edition

Gray, Martin, (2003), The Culture of Literary Terms, Translated by Mansour Sharifzadeh, Tehran, Humanities Research Institute, First Edition
Modaresi, Fatemeh, (2011), Descriptive Culture of Criticism and Literary Theories, Tehran, Humanities Research Institute, First Edition

Moradi, Hadi, (2014), Williamson's Knowledge of Ambiguity, Tarbiat Modarres University, MA Thesis

Musharraf, Maryam, (2003), Semiotics of Mystical Interpretation, Tehran, Third

Maalouf, Lewis, (2007), Al-Mengad, Tehran, Islam Publications, Fourth Edition

Hamadani, Abolmali, (2000), Zebodehul-Haqayeq, Correction of Afif Asiran, Translated by Mehdi Tadin, Tehran, No.1, First Edition

Hamadani, Abolmali, (2006), Defense, Translated by Ghassem Ansari, Tehran, Manouchehri, Second Edition

Hamadani, Abolmali, (2010), Tamhidat, Correction of Asifan, Tehran, Manouchehri, Eighth Edition

First Edition, Jungle Publications, Tehran A Glossary of literary terms,articles 
Periódico do Núcleo de Estudos e Pesquisas sobre Gênero e Direito Centro de Ciências Jurídicas - Universidade Federal da Paraíba V. 8 - No 05 - Ano 2019 ISSN | 2179-7137 | http://periodicos.ufpb.br/ojs2/index.php/ged/index

shiri, Ghahreman, (2011), The Importance and Types of Ambiguities in Research, Journal of Literary Techniques, University of Isfahan, Third Year, No. 2

Yousefi, Mohammad Reza and Rasoulian, Sedigheh, (2013), Symbol of Ambiguity, Literary Techniques, University of Isfahan, Fifth Year, No. 2 